\title{
Synthesis of ent-Seragakinone A
}

Key words

ent-seragakinone $A$

pinacol

rearrangement

aldol reaction

benzoin formation

SYNFACTDath
Significance: Seragakinone A was isolated from an unidentified marine fungus, which is in symbiosis with rhodophyta Ceratodictyon spongiosum, and was shown to exhibit both antifungal and antibacterial properties. The relative structure was determined using X-ray crystal structure analysis and extensive spectroscopic studies; however, the absolute stereochemical configuration was not determined.

SYNFACTS Contributors: Steven V. Ley, Philippa B. Cranwell Synfacts 2011, 6, 0581-0581 Published online: 19.05.2011 DoI: 10.1055/s-0030-1260367; Reg-No.: N02211SF
Comment: Installation of the stereogenic center at $\mathrm{C5a}(\mathbf{D} \rightarrow \mathbf{E})$ was obtained via a pinacol-type rearrangement, which proceeded rapidly in high yield and with efficient transfer of stereochemistry. The benzoin cyclization to afford ketol $\mathbf{J}$ installed the stereocenter at $\mathrm{C}^{\star}$ with excellent diastereoselectivity, which was verified by $\mathrm{X}$-ray crystal structure analysis. 